\title{
Asthma and respiratory symptoms in urban and rural Saudi Arabia
}

\author{
N. Hijazi*, B. Abalkhail*, A. Seaton+
}

Asthma and respiratory symptoms in urban and rural Saudi Arabia. N. Hijazi, B. Abalkhail, A. Seaton. CERS Journals Ltd 1998.

ABSTRACT: The aim of this study was to contrast the prevalence of allergic symptoms in children living in urban and rural areas of Saudi Arabia and to investigate factors associated with any differences found.

A cross-sectional questionnaire survey was conducted of a social class-stratified sample of 1,020 urban and 424 rural 12 yr old children, recording symptoms of current and past allergic disease and doctors' diagnoses, together with nationality and the fathers' educational level and occupations.

A significantly greater prevalence of allergic symptoms was found in urban than in rural children and in Saudi than in non-Saudi Arab children. Males were more likely to have some respiratory symptoms and females had more eye and skin symptoms. Educational level and occupation of the father did not influence the likelihood of having symptoms. Logistic regression analyses showed that urban residence and Saudi nationality were the two main risk factors associated with asthmatic symptoms.

There is likely to have been a recent increase in the prevalence of allergic disease in Saudi children associated with increased affluence, which has not affected non-Saudi migrants moving into the same environment to the same extent. This is consistent with the hypothesis that the environment, possibly through changes in lifestyle and patterns of infection, influences the expression of allergic disease.

Eur Respir J 1998; 12: 41-44.
*Dept of Community Medicine and Primary Health Care, Faculty of Medicine and Allied Science, King Abdulaziz University, Jeddah, Saudi Arabia. +Dept of Environmental and Occupational Medicine, Medical School, University of Aberdeen, Aberdeen, UK.

Correspondence: A. Seaton

Dept of Environmental and Occupational Medicine

Medical School

University of Aberdeen

Foresterhill

Aberdeen AB25 2ZD

UK

Fax: 441224662990

Keywords: Asthma, atopic diseases, children, epidemiology, racial differences, ruralurban differences

Received: October 201997

Accepted after revision March 71998
Asthma continues to cause considerable disability in children and adults throughout the world. It is the most common chronic disease of childhood and an important cause of absence from school and reduced participation in sports and other activities [1]. Several studies, for example in the UK and Australia, have reported a substantial increase in the prevalence of the disease among children over the last three decades [2-7]. While some of this may be due to changes in diagnostic practice, there is general agreement that the increase in prevalence of symptoms is a true phenomenon [8-10]. The change seems to be associated with changes in lifestyle $[11,12]$ and this is supported by studies which have shown an increased prevalence of asthmatic symptoms among people who have moved from a traditional to a more Westernized style of living [13-16].

The disease is now reaching epidemic proportions in Westernized countries, recent studies having reported prevalences of diagnosed asthma among primary schoolchildren in urban Aberdeen, Scotland, of almost $20 \%$ and of exercise-induced bronchospasm in the rural Isle of Skye as high as $30 \%[7,17]$. The causes of the increase in asthma, which appears to have been accompanied by smaller rises in the prevalence of hay fever and eczema, remain unknown. These recent results suggest that urbanization per se is not responsible and one of the present authors has argued that increased population susceptibility rather than changes in exposure to allergens is likely to be the explanation $[18,19]$. The association with a Westernized lifestyle appears to be strong, and changes in diet and patterns of childhood infection at present seem to have been the most likely determinants of the proposed changes in population susceptibility $[11,18,20,21]$.

Saudi Arabia is a country that has developed rapidly over the last three decades as a consequence of the importance of oil to the world's economy. Most people in the population live in large modern cities, in a style far removed from that of their forefathers. Nevertheless, in country districts and villages a much more traditional lifestyle is maintained. Previous studies have suggested that doctor-diagnosed asthma occurs in $4-17 \%$ of urban Saudi children [22, 23].

In a research programme investigating environmental factors related to the causation of asthma, a survey of the prevalence of respiratory symptoms was conducted among children in Saudi Arabia, contrasting both a large city with an undeveloped rural area and also children of Saudi and non-Saudi origin. The results of this survey are reported here.

\section{Methods}

The survey used a validated questionnaire on respiratory symptoms and asthma [24], with additional questions on nationality, place of residence, and father's occupation and education. The questionnaire was translated into Arabic and pilot studies were carried out to ensure its comprehensibility to children in that language. The urban survey took place in Jeddah, a city on the Red Sea coast with a 
population of approximately 1.5 million. A stratified random sample of all schools in the city, representative of all social classes, was taken and all children in the classes for $12 \mathrm{yr}$ olds in these schools were identified. The rural area, also close to the Red Sea and between 180-250 km from Jeddah, was chosen as having similar temperature and humidity and the survey included all children of the same age group in the schools in the villages of Rabegh-Mastourah, Kulia, Hujer, Saber, Alabouak and Maghenia. In total, 49 schools were included, with 1,444 children of the chosen age, 1,097 in Jeddah and 347 in the rural area.

After permission was received from the education authorities and the local schools, individual schools were visited and the questionnaire was read out in the classes and filled in by the children themselves. The questionnaire was checked for completeness at the time of administration by the researcher. The data were coded, entered into a database and analysed using SPSS and chi-squared tests of significance. Stepwise logistic regression was used to investigate the inter-relationships between symptoms and the following variables: area of residence (rural or urban), nationality (Saudi or non-Saudi), sex, and father's educational level (illiterate, primary, secondary or tertiary). The model excluded those variables not significant at the 5\% level.

\section{Results}

All of the 1,444 children identified completed all questions, except for 22 who did not know their father's educational level and/or occupation. The prevalence rates of positive answers in urban and rural areas are shown in table 1, with all symptoms except for dry cough being significantly more frequent in Jeddah than in the villages. In Jeddah, a history of having had asthma was significantly more frequent in males, although wheeze did not differ between the sexes. In contrast, nasal and skin symptoms were more frequent in females. In the villages, cough was more common in males, as was exercise wheeze.

The results were reanalysed after exclusion of 347 children of non-Saudi nationality, all save nine of whom lived in Jeddah. This showed even stronger rural-urban differences (table 2). Although there were significant differences between urban and rural areas in terms of higher parental education and occupation in Jeddah, analysis of these in relation to the prevalence of symptoms showed no associations.

As an index of the severity of asthma, table 3 records the symptoms in those with wheeze in the last year. Of the children in Jeddah, $13.3 \%$ admitted to $>12$ attacks and $32 \%$ had woken with an attack at night more than once per week. Attacks limiting speech had occurred in $41.5 \%$. Those village children with recent wheeze recorded rather more frequent symptoms, but of similar severity.

Table 2. - Prevalence of symptoms (\%) among Saudi nationals in urban and rural areas

\begin{tabular}{lcrc}
\hline Symptoms* & Urban & Rural & $\begin{array}{c}\text { Significance } \\
\text { (p-value) }\end{array}$ \\
\hline Number & 689 & 408 & \\
Asthma ever? & 17.3 & 5.4 & $<0.001$ \\
Wheeze ever? & 21.2 & 7.4 & $<0.001$ \\
Wheeze last year? & 16.4 & 6.4 & $<0.001$ \\
Dry cough? & 19.0 & 12.5 & 0.007 \\
Wheeze with exercise? & 19.5 & 8.1 & $<0.001$ \\
Itchy eyes/nose? & 15.1 & 8.1 & $<0.001$ \\
Itchy skin? & 15.7 & 9.6 & 0.005 \\
Asthma diagnosed? & 17.7 & 4.9 & $<0.001$ \\
Hay fever diagnosed? & 3.4 & 0.2 & 0.002 \\
Eczema diagnosed? & 8.7 & 1.7 & $<0.001$ \\
*: questions as in table 1. & & &
\end{tabular}

Table 3. - Symptoms in those with wheeze in the last year

\begin{tabular}{|c|c|c|c|c|}
\hline \multirow[t]{2}{*}{ Symptoms } & \multicolumn{2}{|c|}{ Urban } & \multicolumn{2}{|c|}{ Rural } \\
\hline & $\mathrm{n}$ & $\%$ & $\mathrm{n}$ & $\%$ \\
\hline \multicolumn{5}{|l|}{ Number of attacks } \\
\hline$<4$ & 87 & 64.4 & 13 & 48.1 \\
\hline $4-12$ & 30 & 22.2 & 12 & 44.4 \\
\hline$>12$ & 18 & 13.3 & 2 & 7.4 \\
\hline Total & 135 & 100 & 27 & 100 \\
\hline \multicolumn{5}{|l|}{ Waking at night } \\
\hline Not awakened & 53 & 39.3 & 4 & 14.8 \\
\hline Once·week ${ }^{-1}$ & 38 & 38.1 & 3 & 48.1 \\
\hline More than once $\cdot$ week $^{-1}$ & 44 & 32.6 & 12 & 37.0 \\
\hline Total & 135 & 100 & 27 & 100 \\
\hline Speech-limiting attack & 56 & 41.5 & 9 & 33.3 \\
\hline
\end{tabular}

Table 1. - Prevalence of respiratory symptoms (\%) in urban and rural areas

\begin{tabular}{|c|c|c|c|c|}
\hline Symptom & Urban & Rural & Total & $\begin{array}{l}\text { Significance } \\
\text { (p-value) }\end{array}$ \\
\hline Numbers of children & 1020 & 424 & 1444 & \\
\hline Have you ever had asthma? & 14.9 & 5.4 & 12.1 & $<0.001$ \\
\hline $\begin{array}{l}\text { Have you ever had wheezing or whistling in your } \\
\text { chest at any time in the past? }\end{array}$ & 17.8 & 7.3 & 14.8 & $<0.001$ \\
\hline $\begin{array}{l}\text { Have you had wheezing or whistling in the chest in the } \\
\text { last } 12 \text { months? }\end{array}$ & 13.2 & 6.4 & 11.2 & $<0.001$ \\
\hline $\begin{array}{l}\text { In the last } 12 \text { months have you had a dry cough at night, } \\
\text { apart from a cough associated with a cold or chest infection? }\end{array}$ & 16.6 & 13.0 & 15.5 & 0.085 \\
\hline $\begin{array}{l}\text { In the last } 12 \text { months, has your chest sounded wheezy during } \\
\text { or after exercise? }\end{array}$ & 16.6 & 8.0 & 13.6 & $<0.001$ \\
\hline $\begin{array}{l}\text { In the last } 12 \text { months, have you suffered from itchy and } \\
\text { running eyes/nose for longer than two weeks? }\end{array}$ & 13.9 & 8.0 & 12.2 & 0.002 \\
\hline $\begin{array}{l}\text { In the last } 12 \text { months, have you suffered from an itchy } \\
\text { rash on your hands or feet? }\end{array}$ & 13.7 & 9.7 & 12.5 & 0.034 \\
\hline \multirow[t]{3}{*}{ Have you ever been told that you have: asthma? } & 15.1 & 5.0 & 12.1 & $<0.001$ \\
\hline & 2.7 & 0.2 & 1.9 & $<0.006$ \\
\hline & 7.7 & 1.7 & 5.9 & $<0.001$ \\
\hline
\end{tabular}


Table 4. - Logistic regression analyses of selected symptoms

\begin{tabular}{llcr}
\hline Symptoms & \multicolumn{1}{c}{ Variable } & Odds ratio & $95 \%$ CI \\
\hline Wheeze ever? & Urban-rural & 1.78 & $1.45-2.18$ \\
& Saudi-non-Saudi & 1.50 & $1.23-1.82$ \\
Wheeze last year? & Male-female & 1.16 & $1.01-1.35$ \\
& Urban-rural & 1.65 & $1.32-2.05$ \\
Asthma ever? & Saudi-non-Saudi & 1.61 & $1.28-2.04$ \\
& Urban-rural & 1.83 & $1.45-2.30$ \\
Itchy eyes/nose? & Saudi-non-Saudi & 1.40 & $1.14-1.72$ \\
& Male-female & 1.27 & $1.07-1.49$ \\
Itchy skin? & Urban-rural & 1.39 & $1.14-1.70$ \\
& Male-female & 0.81 & $0.69-0.95$ \\
& Urban-rural & 1.30 & $1.08-1.57$ \\
\hline
\end{tabular}

CI: confidence interval.

Logistic regression analyses (table 4) showed the two major risk factors for asthmatic symptoms to be urban residence and Saudi nationality. Male sex made a smaller contribution. For itchy hands and feet and itchy eyes, female sex and urban residence were the significant risk factors. Father's educational level made no contribution in any of the models tested.

\section{Discussion}

Saudi Arabia is a country which has moved from a primarily rural to a wealthy urban economy over the past five decades. Asthma and other allergic diseases are recognized to have increased worldwide in association with what is usually referred to as "Westernization", but which is probably greater affluence of society. It was anticipated that a high prevalence of allergic symptoms might be found among people in this country who share in the affluence and the opportunity was taken to compare them with those of common racial stock pursuing more traditional lifestyles. A questionnaire was used that has been well validated in several countries and languages, although this was its first use in Arabic [24]. Continuing studies by the present authors will validate the questionnaire in this language with respect to skin tests and exercise responses, but the present study's finding with respect to similar severity of recorded symptoms in the two areas in spite of different prevalences suggests that it is measuring symptoms in the way that it does in other languages. The possibility of response bias has been considered. Care was taken to administer the questionnaire in the same way in the two areas and the children in the classes did not communicate with each other during the process. There may have been some bias because of the greater sophistication of the city children and this is suggested by the slightly greater frequency of attacks among those rural children who reported symptoms. However, it is unlikely that this could have caused the substantial differences in prevalence.

The three significant positive findings of this study were the two- to threefold difference in asthmatic symptoms between Saudi urban and rural dwellers, the differences in relation to sex, and the excess of symptoms among Saudi as opposed to non-Saudi urban dwellers. In addition, there was one negative result of interest, i.e. the absence of any effect of social or educational class. Of the positive results, the differences between urban and rural children were not surprising (although they remain unexplained) and are similar to those found between children in South Africa, Zimbabwe and, most recently, Ghana and Ethiopia [13, 25-27]. Among the urban children, the prevalence of symptoms appears to be close to that found in Western societies, although in the latter urban-rural differences are not apparent. It is likely that the environmental factors responsible for these contemporary differences will be the same as those that have determined the secular changes in asthma prevalence in Westernized countries.

The differences between indigenous and nonindigenous people sharing the same urban environment were more surprising. The latter differed neither in genetic stock, almost all being Arabs from other Middle Eastern countries, nor in father's educational or occupational level. They were, however, likely to be from somewhat less prosperous families that migrated relatively recently into the Kingdom. The reasons for the differences in symptom prevalence are being explored in the continuing investigations.

Finally, there was no influence of paternal education or occupation on risk of symptoms. This suggests that the urban-rural differences in Saudi Arabia, and by implication the changes found elsewhere, relate to environmental and lifestyle factors other than social class. Of those differences to be investigated, dietary intake of antioxidants and fatty acids, possibly by the mother during pregnancy, and frequency or severity of early childhood infection appear to be the most promising $[20,21,28,29]$.

This research contributes to the ongoing debate about the causes of the increase in allergic disease. Rapid changes in the prevalence of asthma in relation to increasing quality of life have important implications with respect to health service and employment costs and a public health strategy is needed to halt the rise. Recent research has concentrated more on the prevention of exposure to allergens than on the modification of population susceptibility, but it is possible that the latter would be a more promising approach. Accumulating evidence suggests that two factors associated with increased standard of living may be important, i.e. changes in diet and reductions in early childhood infection [11, 20, 29]. If the diets of pregnant females and of very young children (such as by breastfeeding $[30,31])$ were important modifiers of susceptibility to allergic disease, a preventive strategy could be devised. If infection were to prove relevant (and the authors have published evidence that at least the common childhood infections may not be [32]) vaccines or pharmacological manipulation of the mechanisms of expression of the atopic phenotype may prove possible [33]. Studies in 
countries where the change in prevalence is currently occurring will provide important clues as to which directions of research are likely to be most productive.

\section{References}

1. Hill RA, Standen PJ, Tattersfield AK. Asthma, wheezing and school absences in primary schools. Arch Dis Child 1989; 64: 246-251.

2. Peat JK, Haby M, Spijker J, Berry G, Woolcock AJ. Prevalence of asthma in adults in Busselton, Western Australia. BMJ 1992; 305: 1326-1329.

3. Robertson GF, Heycock E, Bishop J, Nolan T, Olinsky A, Phelan PD. Prevalence of asthma in Melbourne schoolchildren: changes over 26 years. BMJ 1991; 302: 11161118.

4. Peat JK, van den Berg RH, Green WF, Mellis CM, Leeder SR, Woolcock AJ. Changing prevalence of asthma in Australian children. BMJ 1994; 308: 1591-1596.

5. Burr ML, Butland BK, King S, Vaughan-Williams E. Changes in asthma prevalence: two surveys 15 years apart. Arch Dis Child 1989; 64: 1452-1462.

6. Ninan TK, Russell G. Respiratory symptoms and atopy in Aberdeen schoolchildren: evidence from two surveys 25 years apart. BMJ 1992; 304: 873-875.

7. Omran M, Russell G. Continuing increase in respiratory symptoms and atopy in Aberdeen schoolchildren. BMJ 1996; 312: 34.

8. Hill RA, Williams J, Tattersfield A, Britton J. Change in use of asthma as a diagnostic label for wheezing illnesses in schoolchildren. BMJ 1989; 299: 898.

9. Britton J. Asthma's changing prevalence. BMJ 1992; 304: 857-858.

10. Burney PGJ, Chinn S, Rona RJ. Has the prevalence of asthma increased in children? Evidence from the national study of health and growth 1973-86. BMJ 1990; 300: 1306-1310.

11. Shaheen SO. Changing patterns of childhood infection and the rise in allergic disease. Clin Exp Allergy 1995; 25: 1034-1037.

12. Woolcock AJ. Asthma - disease of a modern lifestyle. Med J Austral 1996; 165: 358-359.

13. Van Niekerk CH, Wienberg EG, Shore SC, Heese H de V, van Schalkwyk DJ. Prevalence of asthma: a comparative study of urban and rural Xhosa children. Clin Allergy 1979; 9: 319-324.

14. Waite DA, Eyles EF, Tonkin SL, O'Donnell TV. Asthma prevalence in Tokelauan children in two environments. Clin Allergy 1980; 10: 71-75.

15. Cookson JB. Prevalence rates of asthma in developing countries and their comparison with those in Europe and North America. Chest 1987; 91: 97S-103S.

16. Flynn MGL. Respiratory symptoms of rural Fijian and
Indian children in Fiji. Thorax 1994; 49: 1201-1204.

17. Austin JB, Russell G, Adam MG, Mackintosh D, Kelsey S, Peck DF. Prevalence of asthma and wheeze in the Highlands of Scotland. Arch Dis Child 1994; 71: 211-216.

18. Seaton A, Godden DS, Brown K. Increase in asthma - a more toxic environment or a more susceptible population? Thorax 1994; 49: 171-174.

19. Seaton A, Soutar A, Mullins J. The increase in hay fever: pollen, particulate matter and $\mathrm{SO}_{2}$ in ambient air. $Q \mathrm{~J} \mathrm{Med}$ 1996; 89: 279-84.

20. Hodge L, Salome CM, Peat JK, Haby MM, Xuan W, Woolcock AJ. Consumption of oily fish and childhood asthma risk. Med J Austral 1996; 164: 137-140.

21. Soutar A, Seaton A, Brown K. Bronchial reactivity and dietary antioxidants. Thorax 1997; 52: 166-170.

22. Al Frayh A, Bener A, Al Juwadi TQ. Prevalence of asthma among Saudi school children. Saudi Med J 1992; 13: 521-524.

23. Al Frayh A. Asthma patterns in Saudi Arabian children. $J$ $R$ Soc Health 1990; 110: 98-100.

24. Pearce N, Weiland S, Keil U, et al. Self-reported prevalence of asthma symptoms in children in Australia, England, Germany and New Zealand: an international comparison using the ISAAC protocol. Eur Respir $J$ 1993; 6: 1455-1461.

25. Keeley DJ, Neill P, Gallivan S. Comparison of the prevalence of reversible airway obstruction in rural and urban Zimbabwean children. Thorax 1991; 46: 549-553.

26. Yobo EODA, Custovic A, Taggart SCO, Asafo-Agyei AP, Woodcock A. Exercise induced bronchospasm in Ghana: differences in prevalence between urban and rural schoolchildren. Thorax 1997; 52: 161-165.

27. Yemaniberhan H, Bekele Z, Venn A, Lewis S, Parry E, Britton J. Prevalence of wheeze and asthma and relation to atopy in urban and rural Ethiopia. Lancet 1997; 350: 85-90.

28. Shaheen S. Discovering the causes of atopy. Patterns of childhood infection and fetal growth may be implicated. BMJ 1997; 314: 987-988.

29. Black PN, Sharpe S. Dietary fat and asthma: is there a connection? Eur Respir J 1997; 10: 6-12.

30. Burr MJ, Limb ES, Maguire MJ, et al. Infant feeding, wheezing, and allergy: a prospective study. Arch Dis Child 1993; 68: 724-728.

31. Saarinen UM, Kajosaari M. Breastfeeding as prophylaxis against atopic disease: prospective follow-up study until 17 years old. Lancet 1995; 346: 1065-1069.

32. Bodner C, Godden D, Seaton A (on behalf of the Aberdeen WHEASE Group). Family size, childhood infections and atopic diseases. Thorax 1998; 53: 28-32.

33. Holt PG, Sly PD. Allergic respiratory disease: strategic targets for primary prevention during childhood. Thorax 1997; 52: 1-4. 